\title{
Bipolar Disorder and Immune Dysfunction: Epidemiological Findings, Proposed Pathophysiology and Clinical Implications
}

\author{
Joshua D. Rosenblat ${ }^{1,2, *}$ and Roger S. McIntyre ${ }^{1,2}$ \\ 1 Department of Psychiatry, University of Toronto, Toronto, ON M5T 2S8, Canada \\ 2 Mood Disorders Psychopharmacology Unit, University Health Network, 399 Bathurst Street, MP 9-325, \\ Toronto, ON M5T 2S8, Canada; Roger.McIntyre@uhn.ca \\ * Correspondence: joshua.rosenblat@utoronto.ca; Tel.: +1-416-603-5279; Fax: +1-416-603-5368
}

Received: 13 October 2017; Accepted: 27 October 2017; Published: 30 October 2017

\begin{abstract}
Bipolar disorder (BD) is strongly associated with immune dysfunction. Replicated epidemiological studies have demonstrated that BD has high rates of inflammatory medical comorbidities, including autoimmune disorders, chronic infections, cardiovascular disease and metabolic disorders. Cytokine studies have demonstrated that BD is associated with chronic low-grade inflammation with further increases in pro-inflammatory cytokine levels during mood episodes. Several mechanisms have been identified to explain the bidirectional relationship between $\mathrm{BD}$ and immune dysfunction. Key mechanisms include cytokine-induced monoamine changes, increased oxidative stress, pathological microglial over-activation, hypothalamic-pituitary-adrenal (HPA) axis over-activation, alterations of the microbiome-gut-brain axis and sleep-related immune changes. The inflammatory-mood pathway presents several potential novel targets in the treatment of BD. Several proof-of-concept clinical trials have shown a positive effect of anti-inflammatory agents in the treatment of $\mathrm{BD}$; however, further research is needed to determine the clinical utility of these treatments. Immune dysfunction is likely to only play a role in a subset of BD patients and as such, future clinical trials should also strive to identify which specific group(s) of BD patients may benefit from anti-inflammatory treatments.
\end{abstract}

Keywords: bipolar disorder; inflammation; cytokines; depression; neuroprogression; cognition; $\mathrm{N}$-acetylcysteine; infliximab; celecoxib; minocycline

\section{Introduction}

Bipolar disorder (BD) is a severe and persistent mental illness associated with significant morbidity and mortality. While numerous hypotheses have been proposed to explain the underlying patho-etiology of $\mathrm{BD}$, the mechanisms sub-serving disease onset and progression remain largely unknown. More recently, immune dysfunction has been implicated in the patho-etiology of $\mathrm{BD}$ [1]. The hypothesis that immune dysfunction may be a mediator of disease progression in BD was first proposed by Horrobin \& Lieb (1981) [2] who hypothesized that immune modulation may be a key mechanism of action in lithium's mood stabilizing effects. They further hypothesized that the relapsing-remitting nature of BD may be driven by the immune system, as seen in other relapsing-remitting inflammatory disorders, such as multiple sclerosis (MS) [2]. Since their hypothesis was proposed, numerous investigators have studied the interaction between $\mathrm{BD}$ and immune dysfunction [1,3-5].

The primary aim of the current review is to summarize and synthesize studies assessing the interaction between BD and immune dysfunction. Towards this end, we will summarize the following key areas: (1) epidemiological data revealing high rates of comorbidity between BD and inflammatory disorders; (2) cytokine studies showing increased central and peripheral levels of pro-inflammatory 
molecules in BD compared to healthy controls; (3) proposed pathophysiological mechanisms sub-serving the inflammatory-mood pathway and (4) clinical implications of the interaction between $\mathrm{BD}$ and immune dysfunction, with a focus on repurposing anti-inflammatory agents in the treatment of bipolar depression.

Of note, the current review is not a systematic review, but rather narrative in nature, to provide a broad overview of the topic. A systematic review was not conducted given the breadth of the topic and vast number of studies on the various elements of the interactions between BD and inflammation. As such, the authors decided to focus on particularly relevant studies rather than exhaustively reviewing all published articles. The authors acknowledge that this approach is vulnerable to the presentation of a biased perspective; however, have attempted to present in an unbiased manner, highlighting areas of controversy and disagreement when needed.

\section{Bipolar Disorder and Inflammatory Comorbidities}

One potential indicator to suggest an interaction between BD and immune dysfunction is the high rates of inflammatory medical comorbidities in $\mathrm{BD}$ [6]. The association between $\mathrm{BD}$ and inflammatory comorbidities has been well established in numerous epidemiological studies; however, the direction of causality remains somewhat unclear. As shown in Figure 1a, immune dysfunction may be a common underlying cause of both BD and an inflammatory comorbidity in a given patient. Alternatively, BD may proceed the inflammatory condition or vice versa (Figure $1 b, c$ ). All three scenarios are observed in the $\mathrm{BD}$ population suggesting that the interaction is likely bidirectional in that immune dysfunction, $\mathrm{BD}$ and inflammatory comorbidities may be perpetuating each other as shown in Figure 1d [6]. Further, genetic and environmental risk factors for immune dysfunction may simultaneously increase the risk of developing both $\mathrm{BD}$ and other inflammatory comorbidities. Herein we summarize pertinent epidemiological findings showing the association between BD and inflammatory comorbidities.
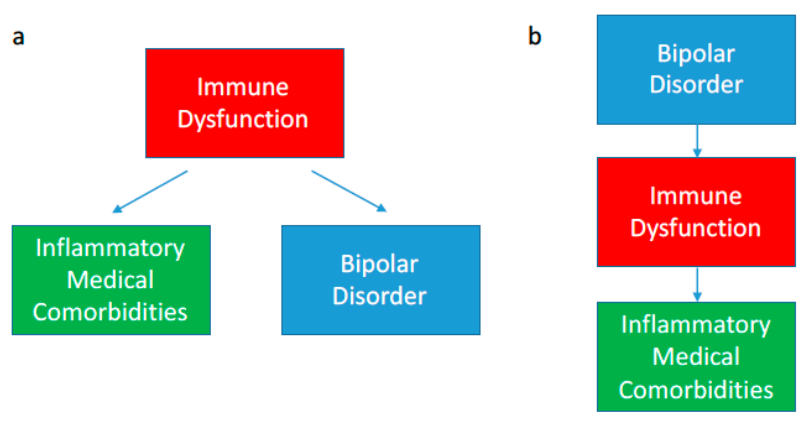

d

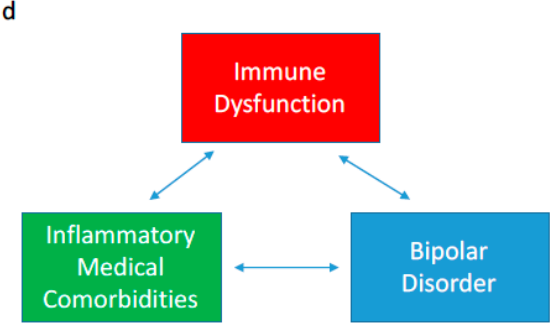

Figure 1. Potential interactions between bipolar disorder (BD), immune dysfunction and inflammatory comorbidities. (a) Immune dysfunction may be a common underlying cause of both BD and an inflammatory comorbidity; (b) BD may proceed the inflammatory condition or (c) vice versa. All three scenarios are observed in the BD population suggesting that the interaction is likely bidirectional in that immune dysfunction, BD and inflammatory comorbidities may be perpetuating each other (d).

When an inflammatory comorbidity is present, peripherally released pro-inflammatory cytokines may increase systemic cytokine levels (e.g., IL-2, IL-6, TNF- $\alpha$ ) throughout the body, including in 
the brain [7]. The subtler effects of chronic low grade systemic inflammation on off-target areas (e.g., the brain) has been increasingly recognized as important [8,9]. Admittedly, the association between $\mathrm{BD}$ and inflammatory comorbidities does not, in itself, prove causation, however, the biological mechanisms [10] to be further discussed in Section 4 provide further evidence that these epidemiological observations (summarized in Table 1) are likely to be more than just spurious associations.

Table 1. Inflammatory comorbidities associated with bipolar disorder, as shown by epidemiological studies.

\begin{tabular}{|c|c|}
\hline Category & Specific Conditions \\
\hline Autoimmune disorders & $\begin{array}{c}\text { Inflammatory bowel disease (IBD) } \\
\text { Systemic lupus erythematosus (SLE) } \\
\text { Autoimmune thyroiditis } \\
\text { Guillain-Barré syndrome (GBS) } \\
\text { Autoimmune hepatitis } \\
\text { Rheumatoid arthritis (RA) } \\
\text { Multiple sclerosis (MS) } \\
\text { Psoriasis }\end{array}$ \\
\hline Chronic infections & $\begin{array}{c}\text { Toxoplasma gondii (T. gondii), } \\
\text { Possibly herpes simplex virus } 1 \text { (HSV1), } \\
\text { cytomegalovirus (CMV) and human herpes virus } 6 \text { (HHV6) }\end{array}$ \\
\hline Cardiovascular disease & $\begin{array}{c}\text { Myocardial infarction } \\
\text { Stroke } \\
\text { Atherosclerosis } \\
\text { Hypertension }\end{array}$ \\
\hline \multirow{5}{*}{ Metabolic disorders } & Type II diabetes mellitus \\
\hline & Dyslipidemia \\
\hline & Central obesity \\
\hline & Metabolic syndrome \\
\hline & Gout \\
\hline
\end{tabular}

\subsection{Bipolar Disorder and Autoimmune Disorders}

Autoimmune disorders represent the most "classic" of inflammatory conditions in that they are defined by the presence of immune dysfunction. In brief, autoimmune disorders occur when the immune system misrecognizes host tissue as pathogenic and attempts to remove the misidentified host tissue [11]. In doing so, both a local and systemic inflammatory response is initiated. Locally, the immune system attempts to break down and clear the triggering tissue (e.g., local break down of skin in psoriasis). While triggering this local inflammatory response, pro-inflammatory cytokines are released and circulated systemically with some degree of penetration to the central nervous system (CNS) as well. As a group, autoimmune disorders have been identified to occur at increased rates in BD [6]. Epidemiological studies have consistently shown increased rates of inflammatory bowel disease (IBD), systemic lupus erythematosus (SLE), autoimmune thyroiditis, psoriasis, Guillain-Barré syndrome (GBS), autoimmune hepatitis, MS and rheumatoid arthritis (RA) in BD [12-18].

\subsection{Bipolar Disorder and Chronic Infections}

Infections are also classically associated with both a local and systemic inflammatory response. The inflammatory response to infections is an essential physiological response that has been evolutionarily conserved amongst all mammal species [11]; however, in the case of chronic infections, the prolonged inflammatory response may also have deleterious effects, as the immune response is best suited for clearing an acute infection [19]. Similar to autoimmune disorders, chronic infections 
may lead to chronic elevation of pro-inflammatory cytokines systemically and centrally. As such, an association between chronic infections and BD may be expected.

Dating back to the 19th century, there has been significant interest in the interaction between $\mathrm{BD}$ and chronic infections, such as Toxoplasma gondii (T. gondii), herpes simplex viru 1 (HSV1), cytomegalovirus (CMV) and human herpes virus 6 (HHV6); however, results have been mixed with poor replicability of identified associations [20]. The strongest replicated evidence has shown an increased co-prevalence of $T$. gondii in BD compared to the general population (odds ratio (OR) 1.52, $p=0.02$ ) [21]. Interestingly, chronic infections, such as T. gondii, CMV and HSV1 have been associated with poorer cognitive function in BD [22,23]. Taken together, the association between $\mathrm{BD}$ and chronic infections remains unclear; however, $\mathrm{BD}$ patients with comorbid chronic infections may be at risk for a more severe phenotype secondarily to the presence of chronic low grade inflammation.

\subsection{Bipolar Disorder and Cardiovascular Disease}

Immune dysfunction is a key feature of cardiovascular disease (CVD) as inflammation plays a significant role in the progression of atherosclerotic plaques [24]. Cardiovascular disease has been strongly associated with BD in a bidirectional fashion. To emphasize the importance of this association, the American Heart Association (AHA) has recently recognized BD as an independent risk factor of early CVD. Indeed, replicated epidemiological studies have identified BD as an independent risk factor for CVD and vice versa [25-30]. Both cardiovascular and psychiatric researches have pointed to immune dysfunction as a likely key factor mediating this observed interaction. The high rate of comorbid $\mathrm{BD}$ and CVD is of particular importance because of its role in early mortality in $\mathrm{BD}$; the increased prevalence of CVD is primarily responsible for the 10- to 20-year decrease in life expectancy in BD compared to the general population [31]. With this interaction in mind, some investigators have suggested that targeting immune dysfunction in this patient population may serve to simultaneously improve outcomes for BD, CVD and overall life expectancy $[1,28]$.

\subsection{Bipolar Disorder and Metabolic Disorders}

Similar to CVD, immune dysfunction plays a key role in the progression of metabolic disorders $[26,32,33]$. Diabetes and central obesity have both been associated with chronic low grade inflammation, with the degree of inflammation being directly correlated with disease progression [34]. With immune dysfunction as a likely key mediating factor, BD has been strongly associated with increased rates of diabetes, obesity, dyslipidemia and metabolic syndrome [12,35,36].

A key factor facilitating chronic inflammation related to metabolic disorders is the presence of visceral adipose tissue (i.e., central obesity). Visceral adipose tissue is a direct source of chronic low-grade inflammation, increasing the production of pro-inflammatory adipokines and cytokines including IL-6, TNF- $\alpha$, and C-reactive protein (CRP) [37,38]. Subcutaneous adipose tissue serves as a "metabolic sink" to prevent accumulation of visceral adipose tissue; however, under certain genetic (e.g., polygenic risk factors for central obesity) and environmental (e.g., sedentary lifestyle and poor diet) conditions, high volumes of dysfunctional visceral adipose tissue may accumulate $[37,38]$. In the context of chronic positive energy balance (e.g., greater caloric intake then expenditure), adipocytes undergo hypertrophy and have increased triglyceride stores [39]. The lypolytic rate is therefore increased leading to increased production of leptin (pro-inflammatory) and decreased production of adiponectin (anti-inflammatory), thereby signaling the release of pro-inflammatory cytokines [40]. Further, adipocyte hypertrophy promotes macrophage infiltration of adipose tissue. The resultant cross talk between macrophages and adipocytes promotes further release of pro-inflammatory cytokines and adipokines [37-40].

Bipolar disorder has also been associated with a slightly increased risk of developing gout [41]. With this epidemiological observation in mind, several investigators have recently hypothesized that purinergic system abnormalities and related variations of uric acid may be involved in the pathophysiology of BD $[42,43]$. Uric acid has been strongly associated with other metabolic disorders, 
increased oxidative stress and inflammation [44,45]. Further, several proof-of-concept clinical trials have identified a potential anti-manic effect of drugs lowering uric acid (e.g., allopurinol) [46].

\section{Cytokine Changes Associated with Bipolar Disorder}

Cytokines are signaling molecules of the immune system which may increase or decrease local and systemic inflammatory responses. Measuring cytokine levels peripherally (i.e., serum levels) and centrally (i.e., cerebral spinal fluid (CSF) levels) provides insight into immune system activity. Cytokine levels can identify current levels of inflammation and identify which specific part of the immune system is over or underactive leading to the observed immune dysfunction in BD. Moreover, as signaling molecules, specific cytokines may be directly implicated in the pathophysiology of BD and may therefore present as potential novel targets of treatment.

Cytokine levels have significant fluctuations and variability; however, some trends have emerged through numerous cytokine studies of BD patients compared to healthy controls [3,4]. These cytokine studies have consistently shown elevated levels of pro-inflammatory cytokines in $\mathrm{BD}$, suggestive of chronic low grade inflammation. Serum levels of pro-inflammatory molecules including interleukin-4 (IL-4), tumor necrosis factor alpha (TNF- $\alpha$ ), soluble interleukin-2 receptor (sIL-2R), interleukin-1 beta (IL-1 $\beta$ ), interleukin-6 (IL-6), soluble receptor of TNF- $\alpha$ type 1 (STNFR1) and CRP are elevated in BD patients compared to healthy controls $[3,47-49]$. This cytokine profile indicates dysfunction of the innate immune system.

Another key observation has been variability in cytokine profiles depending on mood state (i.e., differing cytokine profiles during periods of depression, mania, hypomania and euthymia). This variability in cytokine profiles might suggest variable involvement of immune dysfunction in depression versus mania versus euthymia. Significant heterogeneity in BD cytokine studies has been problematic and, as such, there has been no clear cytokine profile that is reproducibly associated with each mood state [3,4]. This significant heterogeneity also suggests that inflammation is likely a pertinent pathogenic factor for only a subset of BD; this subset of BD may potentially represent an "inflammatory-BD" that may be pathophysiologically dissimilar from other BD patients. This potential sub-typing of $\mathrm{BD}$ is currently being investigated with important treatment implications.

Within the context of this substantial heterogeneity, the following mood-dependent cytokine profiles have been identified. The most robust evidence exists for an association between pro-inflammatory cytokines and depressive episodes, in both bipolar and unipolar depression [50]. During depressive episodes, serum levels of CRP, TNF- $\alpha$, IL-6, IL-1 $\beta$, sTNFR1 and CXCL10 are elevated $[10,47,51]$. Increased depression severity is associated with greater elevations of pro-inflammatory cytokines [52]. During manic episodes, serum levels of IL-6, TNF- $\alpha$, sTNFR1, IL-RA, CXCL10, CXCL11 and IL-4 are often elevated [47,51]. During euthymic periods, sTNFR1 is the only consistently elevated inflammatory marker $[47,48]$. One significant limitation of these cytokine studies is their cross-sectional nature (i.e., serum levels are usually only taken at one point in time). Longitudinal studies are needed to measure cytokine levels within the same group of BD subjects to determine how they change during and in between mood episodes. Understanding this chronological relationship (e.g., if cytokines are elevated prior to versus after mood episode onset) would also provide further insight into the cross-talk between $\mathrm{BD}$ and immune dysfunction.

\section{Pathophysiology of the Inflammatory-Mood Pathway}

Numerous mechanisms have been identified which may mediate the bidirectional interaction between BD and immune dysfunction. Many of these mechanisms have been largely established in animal models [53]. More recently, clinical studies have provided evidence to suggest that these preclinical findings are valid in humans as well $[10,54]$. Herein we describe some of the key biological mechanisms which may contribute to the inflammatory-mood pathway. Of note, many of these mechanisms are not exclusive to BD and may trans-diagnostically sub-serve the interactions observed between immune dysfunction and other brain disorders (e.g., unipolar depression, schizophrenia, 
neurodegenerative disorders) [55]. Currently, it remains unclear the degree of overlap versus divergence in inflammatory processes mediating the interaction between immune dysfunction and various neuropsychiatric disorders [56]. We hypothesize that there are likely both trans-diagnostically shared immune pathways as well BD-specific immune pathways (i.e., immune changes and mechanism that may not be present in other disorders).

Central to the inflammatory-mood pathway is the ability of peripherally circulating cytokines to traverse the blood-brain-barrier (BBB). Systemically circulating cytokines may traverse the BBB via active transport channels and through leaky regions of the BBB [57]. Of note, the relative permeability of the BBB for various cytokines remains unclear; however, replicated evidence has demonstrated clear associations between elevation of cytokines in serum samples (i.e., peripherally circulating cytokines) with the same cytokines being elevated in cerebral spinal fluid (CSF) samples (i.e., cytokine levels in the CNS), suggesting that likely all cytokines may penetrate the CNS to some degree [47]. Recent findings in animal models have also suggested the presence of lymphatic vessels in the brain which could provide another direct pathway for cytokines and other signalling molecules to enter the CNS [58]. Cytokines may then signal several downstream effects which alter the structure and function of key brain regions sub-serving mood and cognitive function. Cytokines can directly alter monoamine levels, cause over-activation of microglial cells and lead to increased oxidative stress in the brain [53]. The net effect of these changes is neurodegeneration and decreased neuroplasticity in key brain regions which may lead to the phenotypic changes observed in $\mathrm{BD}$ and other brain disorders.

\subsection{Cytokine-Induced Neurotransmitter Changes}

Monoamine changes have been the focus of mood disorder research for many years. Further, the majority of psychiatric medications' primary mechanism of action is through alteration of monoamine levels [59]. Pro-inflammatory cytokines may directly and indirectly alter monoamine levels in the CNS through numerous pathways. More specifically, TNF- $\alpha$, IL-2 and IL-6 have been shown to directly alter monoamine levels [60]. IL-2 and interferon-gamma and alpha (IFN- $\gamma$ and $-\alpha$ ) increase the enzymatic activity of indolamine 2,3-dioxygenase (IDO), thereby increasing the breakdown of tryptophan to depressogenic tryptophan catabolites (TRYCATs). Serotonin (5-HT) levels may be further modulated through the IL-6 and TNF- $\alpha$ dependent breakdown of 5-HT to 5-hydroxyindoleacetic acid (5-HIAA) [61]. Depletion of tryptophan and decreased levels of 5-HT can directly impair affective and cognitive function [62].

Inflammation may also directly alter levels of dopamine and norepinephrine. Pro-inflammatory molecules, such as IFN, induce the activation of the guanosine-triphosphate-cyclohydrolase-1 (GTP-CH1) enzyme. Increased expression of GTP-CH1 results in the formation of neopterin and tetrahydrobiopterin (BH4), a cofactor used by phenylalanine hydroxylase (PH), tyrosine hydroxylase (TH) and tryptophan hydroxylase (TPH) to form tyrosine (Tyr), dopamine, norephinephrine, and serotonin, respectively; however, inflammation lowers pyruvoyl tetrahydropterin synthase (PTPS) activity, thus favouring neopterin formation instead of BH4 [63-65]. With decreased BH4 levels, the activity of $\mathrm{PH}, \mathrm{TH}$ and TPH is decreased thus lowering the production of dopamine, norepinephrine and serotonin $[55,66,67]$.

Taken together, pro-inflammatory signaling may decrease the levels of dopamine, norepinephrine and serotonin, which has long been associated with worsening mood and cognitive symptoms. Current pharmacotherapies target the end result of this pathway, namely, monoamine levels [59]. Targeting inflammation may have more disease modifying potential as immune dysfunction is "upstream" of the monoamine changes observed in mood disorders; correcting the underlying cause (i.e., immune dysfunction) may provide greater benefits than only treating symptomatically by correcting the downstream effect (i.e., monoamine changes).

Of recent interest has also been the potential interaction between inflammation and another key neurotransmitter, namely, glutamate. The importance of the glutamate system in mood disorder pathophysiology has been highlighted by the robust evidence demonstrating the rapid and 
potent antidepressant effects of ketamine, an N-methyl-D-aspartate (NMDA) glutamate receptor antagonist $[68,69]$. Significant cross-talk between glutamate and the immune system has now been demonstrated in pre-clinical and clinical models [70]. Inflammatory cytokines have been shown to influence glutamate metabolism through direct effects on microglia and astrocytes. As such, inflammatory cytokines may increase glutamate levels thus causing abnormal over-activation of glutamate receptors leading to uncontrolled increases of calcium influx through NMDA receptor channels, with the final result of excitotoxicity and impaired neuroplasticity [71].

The administration of exogenous pro-inflammatory cytokines has been shown to increase glutamate levels in the basal ganglia and anterior cingulate cortex (key brain regions sub-serving mood disorder pathology) as measured by magnetic resonance spectroscopy (MRS) [72]. Further, MRS studies in patients with unipolar depression have revealed that increased markers of inflammation (e.g., CRP) correlate with increased glutamate levels in the basal ganglia, which was specifically associated with anhedonia and psychomotor retardation [73]. In addition, an antidepressant response to ketamine may be predicted by elevated baseline inflammatory markers [74,75], further suggestive of significant cross-talk between immune dysfunction, the glutamate system and mood disorder pathophysiology.

\subsection{Pathological Microglial Over-Activation}

Microglia are the macrophages of the CNS that serve an important role in facilitating neuroplasticity [76-78]. Microglia aid in the pruning of unused neural circuits to allow for more space and energy to be made available for more frequently used neural circuits. Under physiological conditions, microglia may effectively prioritize the most important neural circuits leading to optimal brain structure and function $[77,78]$. However, with chronic inflammation, pro-inflammatory cytokines promote prolonged over-activation of microglia [76]. With this over-activation, microglia may aberrantly prune important neural circuits sub-serving mood and cognitive function (e.g., prefrontal cortex (PFC), amygdala, hippocampus, insula and the anterior cingulate cortex (ACC)) $[76,79]$. This process results in a positive feed-forward loop whereby activated microglia release cytokines, which further increases inflammation and further microglia recruitment and activation. The release of cytokines from activated microglia may also further perpetuate the previously discussed monoamine changes. Lastly, the over-activation of microglia increases the production of reactive oxygen species (ROS) leading to local oxidative stress, further damaging neural circuitry in key brain regions sub-serving mood and cognition [80]. This unfortunate cascade may contribute to the neuroprogression of BD as increasing numbers of important neural circuits are destroyed [47,81-83].

\subsection{Inflammation and Increased Oxidative Stress}

Oxidative stress has also been associated with mood disorders and is intimately connected with immune dysregulation, as inflammation increases oxidative stress and oxidative stress increases inflammation [84-86]. Oxidative stress occurs when there is an imbalance between the production of ROS and production of antioxidants responsible for neutralizing ROS [87]. Replicated evidence has demonstrated increased ROS and decreased antioxidants in BD, leading to pathologic neurodegeneration in key brain regions sub-serving mood and cognition [88-90]. Mood disorders have been associated with increased levels of pro-oxidant markers, namely, 8-hydroxy-2'-deoxyguanosine (8-OHdG), F2-isoprostanes, malondialdehyde (MDA) and decreased levels of anti-oxidant molecules, namely, glutathione (gamma-glutamyl-cysteinyl-glycine; GSH), superoxide dismutase (SOD) and glutathione peroxidase (GPx) [91]. Further, in unipolar depression, antidepressant response (to conventional antidepressants) has been associated with decreased oxidative stress, suggesting a mediational role of oxidative stress reduction in the effective treatment of mood disorders [87]. As such, there has been great interest in further understanding the mechanisms sub-serving increased oxidative stress along with the potential novel drug targets these mechanisms may offer. 


\subsection{Hypothalamic-Pituitary-Adrenal (HPA) Axis Over-Activation}

Pro-inflammatory cytokines, namely IFN, TNF- $\alpha$ and IL-6, significantly up-regulate HPA activity thereby increasing systemic cortisol levels [92]. Under physiological conditions, HPA activation is advantageous to aid in the stress response required with an acute infection or injury. However, with chronic inflammation, HPA activation may be prolonged with deleterious effects related to chronic hypercortisolemia [93]. Additionally, chronic hypercortisolemia leads to downregulation of glucocorticoid receptor synthesis, translocation and sensitivity in the pituitary and hypothalamus, effectively inhibiting the negative feedback loop of the HPA axis [94]. This loss of the negative feedback loop leads to further propagation of hypercortisolemia with the well-established negative downstream effects (e.g., mood, cognitive and physical squealy) of chronically elevated cortisol levels [95-98]. Further, impaired cortisol suppression itself has long been recognized a strong predictor of mood disorders [98].

Dysfunction of the HPA axis has been identified in numerous medical and psychiatric disorders, however, the particular relevance in $\mathrm{BD}$, in specific, was further emphasized by a recent meta-analysis and systematic review [99]. Belvederi Murri et al., (2016) identified forty-one studies showing that BD was consistently associated with significantly increased levels of cortisol (basal and post-dexamethasone) and adrenocorticotropic hormone (ACTH), but not of corticotropin-releasing hormone (CRH). These authors suggested that progressive HPA axis dysfunction is a putative mechanism that might underlie the clinical and cognitive deterioration of patients with BD and that targeting the HPA axis might be a novel strategy to improve the outcomes of BD [99].

\subsection{The Microbiota-Gut-Brain Axis}

In recent years, the role of the microbiota-gut-brain axis in neuropsychiatric disorders has become of great interest [100-102]. The gut and brain may communicate in a bidirectional fashion through numerous pathways including via the parasympathetic nervous system (primarily the vagus nerve), the gut neuroendocrine system, the circulatory system (delivering neuroactive metabolites and neuro-transmitters directly produced in the gut), and most notably, via the immune system [101]. The composition of the gut microbiota may have a large impact on the signaling molecules, including cytokines, that are being produced by the gastrointestinal (GI) system. The GI system may induce the production of pro-inflammatory cytokines on an acute or chronic basis. These cytokines may have direct effects on brain function as previously described.

Numerous investigators are questioning the potential impact of altering the gut microbiota on immune function and mental illness [103]. While this field is still in its infancy, the potential for novel treatments targeting the gut microbiota to treat BD may represent a completely new class of hypothesis-driven therapeutic interventions. For example, in a recent case report, Hamdani et al., (2015) suspected that a manic episode may have been triggered by alteration of the gut microbiota [104]. Given their hypothesis that the manic episode was triggered by perturbation of the gut-brain axis, the patient was treated with daily activated charcoal (a potent absorbent of gut inflammatory cytokines) instead of conventional anti-manic agents. The manic episode was successfully treated which corresponded to decreased serum levels of pro-inflammatory cytokines and chemokines. While targeting the microbiota to treat $\mathrm{BD}$ has yet to be assessed in any clinical trials, this case reports shows promise for a potential role of this novel target.

\subsection{Inflammation and Sleep Dysfunction}

Sleep dysfunction is a key feature of BD. During all phases of illness, changes in sleep patterns are commonly reported [105]. Indeed, during manic or hypomanic episodes, there is a characteristic decreased need for sleep. During depressive episodes, there may be difficulties achieving adequate quality or quantity of sleep or alternatively, hypersomnia in which patients are sleeping many more hours than would be typical for the general population. Even during euthymic periods, sleep 
complaints are still common in BD [105]. Sleep dysfunction is also strongly associated with immune dysfunction. Replicated evidence has demonstrated sleep dysfunction to be associated with increased levels of pro-inflammatory cytokines with a bidirectional causal association identified [106,107]. As such, interest has grown in immune dysfunction as a potential nexus sub-serving the bidirectional interaction between sleep dysfunction and BD [108,109].

\section{Clinical Implications}

Currently available treatments for BD have poor long term outcomes with high rates of treatment resistance and relapse [110]. Additionally, tolerability is often poor with significant adverse effects, such as weight gain and insulin resistance, being common with most evidence-based treatments [111]. Given the significant interaction between immune dysfunction and $\mathrm{BD}$, the immune system presents as a potential novel target in the treatment of $\mathrm{BD}$. The evidence discussed above suggests that inflammation may play a direct effect in the pathophysiology of BD in a subset of patients. Therefore, repurposing anti-inflammatory agents in the treatment of BD may potentially have disease modifying effects by targeting the underlying etiological processes rather than only treating symptomatically (i.e., the current approach).

Several proof-of-concept clinical trials have assessed the antidepressant effects of anti-inflammatory agents in the treatment of both unipolar [112] and bipolar [113] depression. In a recent meta-analysis conducted by our group to evaluate the antidepressant effects of anti-inflammatory agents, we identified eight randomized clinical trials (RCTs) $(n=312)$ assessing adjunctive nonsteroidal anti-inflammatory drugs $(n=53)$, omega-3 polyunsaturated fatty acids $(n=140)$, N-acetylcysteine, $(n=76)$, and pioglitazone $(n=44)$ in the treatment of BD. The overall effect size of adjunctive anti-inflammatory agents on depressive symptom severity was -0.40 (95\% confidence interval -0.14 to $-0.65, p=0.002)$, indicative of a moderate antidepressant effect with good overall tolerability [113]. The clinical applicability of this meta-analysis was limited by the small number of studies included and small pooled sample size; however, this analysis provided further proof of concept that targeting the immune system may be an efficacious novel treatment for BD. Herein we further summarize clinical trials assessing specific anti-inflammatory agents in the treatment of BD.

\subsection{N-Acetyl-Cysteine (NAC)}

Among all anti-inflammatory agents, NAC has the strongest evidence as an adjunctive treatment for bipolar depression [114,115]. In an RCT of NAC for BD $(n=75)$, adjunctive NAC was shown to lower depression severity scores throughout the trial with a statistically and clinically significant difference compared to conventional therapy alone at the primary endpoint of 24 weeks [114]. Additionally, post-hoc analysis of 17 participants from this sample who met criteria for a current major depressive episode (MDE) at baseline revealed that 8 of 10 participants in the NAC group had a clinical response (i.e., greater than $50 \%$ reduction in depression severity) compared to only 1 of 7 participant in the placebo group [116]. An eight-week open-label trial of NAC also showed antidepressant effects in BD [117]. The effect of adjunctive NAC in mania/hypomania was also explored in a small post-hoc analysis of $15 \mathrm{BD}$ participants experiencing an acute manic/hypomanic episode comparing participants receiving adjunctive NAC $(n=8)$ versus adjunctive placebo $(n=7)$. This analysis revealed a greater improvement in symptoms of mania in the NAC group compared to placebo [118]. Overall, NAC shows promise as an adjunctive treatment for BD during all phases of illness; however, evidence is strongest for use in the acute treatment of bipolar depression.

\subsection{Omega-3 Polyunsaturated Fatty Acids (Omega-3s)}

Several RCTs have also evaluated the effects of adjunctive omega-3s, a naturally-occurring and well-tolerated anti-inflammatory agent [119]. Results have been mixed with some trials showing an antidepressant effect in BD [120,121] and others reporting no antidepressant effect compared to 
conventional therapy alone [122-124]. When pooling these results together in a recent meta-analysis, a moderate and statistically significant anti-depressant effect of adjunctive omega-3s in BD was found compared to conventional therapy alone [119].

The mixed results of these studies assessing omega-3s in BD may suggest that omega-3s are beneficial in only a subset of $\mathrm{BD}$. This hypothesis was further supported by a recent study assessing the antidepressant effects of omega-3s in the treatment of unipolar depression [125]. In this RCT, omega-3s were found to have a significant antidepressant effect in participants with elevated inflammatory markers. Intriguingly, in participants with normal cytokine levels, placebo had a greater antidepressant effect, compared to omega-3s, leading to an overall negative study outcome (i.e., no significant antidepressant effect was found when including the entire sample). While this study was in unipolar depression, it is likely that a similar effect may be observed in $\mathrm{BD}$, in that only patients with elevated inflammatory markers may benefit from omega-3s, however, further study is still required to confirm or refute this hypothesis in the BD population.

\subsection{Non-Steroidal Anti-Inflammatory Drugs (NSAIDs)}

The anti-depressant effect of adjunctive NSAIDs has also been evaluated in BD. Nery et al., assessed adjunctive celecoxib in $\mathrm{BD}(n=28)$ during an acute depressive or mixed episode [126]. Adjunctive celecoxib lowered depression severity by week 1 ; however, the primary outcome was negative as change in depression severity converged with the placebo group by the end of week 6 . Saroukhani et al., assessed the effect of adjunctive aspirin in an RCT with male BD patients $(n=32)$ and found no significant difference between treatment groups by the primary endpoint of 6-weeks [127].

Three studies have also evaluated the effect of NSAIDs during acute manic/hypomanic episodes. In a small, proof-of-concept RCT, Arabzadeh et al., compared adjunctive celecoxib to treatment as usual for acute mania in BD inpatients $(n=46)$ [128]. They observed a significantly higher remission rate in the celecoxib group $(87.0 \%)$ compared to the placebo group (43.5\%) by the week 6 primary endpoint $(p=0.005)$. The same investigators also evaluated adjunctive celecoxib in an RCT of adolescent inpatients $(n=42)$ during an acute manic episode [129]. There was no significant difference in remission rates by the primary endpoint of 8-weeks, however, significantly greater improvement was observed in Young Mania Rating Scale (YMRS) scores in the celecoxib group compared with the placebo group by the week 8 primary endpoint $(p=0.04)$. In another RCT including BD inpatients $(n=35)$ with mania receiving electroconvulsive therapy $(\mathrm{ECT})$, participants received either celecoxib or placebo from one day before the first ECT session throughout the sixth session. Brain-derived neurotrophic factor (BDNF) levels were also measured before and during the trial. Adding celecoxib was not associated with a significant rise in BDNF levels following ECT. No difference was noted between groups in terms of treatment response [130].

Taken together, the effect of NSAIDs in bipolar depression remains unclear as clinical studies have yielded mixed results. Additionally, adjunctive NSAIDs in the treatment of mania has yielded mixed results with anti-manic effects yet to be consistently demonstrated.

\subsection{Minocycline}

Minocycline is a tetracycline antibiotic with potent anti-inflammatory and neuroprotective effects [131]. Since the first case report of minocycline for bipolar depression was published in 1996 [132], there has been significant interest and off-label prescribing of minocycline for bipolar and unipolar depression; however, until this year (2017) there were no published RCTs to support or refute the antidepressant effects of minocycline. Recently, several open label trials and RCTs have been conducted to evaluate the antidepressant effects of minocycline for bipolar and unipolar depression [133-137]. In a recently published pilot, open-label, 8-week study, Soczynska et al., (2017) evaluated the efficacy, safety and tolerability of adjunctive minocycline for the treatment of bipolar I/II depression [134]. Adjunctive minocycline was associated with a significant reduction in depressive symptom severity from baseline to week 8 with overall good tolerability. While there has yet to be an 
RCT of minocycline for bipolar depression, these results show promise for a significant antidepressant effect and merit further investigation.

\subsection{TNF- $\alpha$ Inhibitors}

TNF- $\alpha$ inhibitors have also been of interest as they may directly target a key cytokine (i.e., TNF- $\alpha$ ) known to be implicated in the inflammatory-mood pathway. One pivotal RCT assessed infliximab in treatment resistant depression $(n=60)$, including both bipolar and unipolar depressed patients in their sample. Although the overall antidepressant effect was negative for this study, a significant antidepressant effect was observed for a subgroup of participants, namely, those with elevated levels of serum CRP and TNF- $\alpha$ [138]. Similar to the previously discussed omega-3 RCT [125], the results of this trial suggested that stratification using inflammatory biomarkers might help determine which patients may benefit from anti-inflammatory treatments. A 12-week RCT evaluating the effects of adjunctive infliximab for the treatment of BD patients with elevated inflammatory markers is currently underway, directly implementing this type of stratified approach (NCT02363738).

\subsection{Anti-Inflammatory Effects of Conventional Mood Stabilizers}

Also of interest has been understanding the relative impact of conventional mood stabilizers on the immune system. Indeed, as previously discussed, the initial hypothesis of conceptualizing BD as an immune disorder was developed through observing the immune-modulating effects of lithium, one of the oldest and most effective treatments of BD [2]. The interaction between lithium and the immune system is complex as lithium has been shown to have both anti-inflammatory (e.g., suppression of cyclooxygenase- 2 expression, inhibition of IL- $1 \beta$ and TNF- $\alpha$ production, and enhancement of IL- 2 and IL-10 synthesis) and pro-inflammatory effects (e.g., induction of IL-4, IL-6 and other pro-inflammatory cytokines synthesis) $[139,140]$. As such, the 'net effect' of lithium on immune function may vary greatly; however, long term lithium use has been associated with normalization of cytokine levels [141].

Compared to lithium, much less in know about the impact of valproic acid on the immune system. Pre-clinical studies have suggested possible anti-inflammatory effects of valproic acid, however, clinical studies have failed to demonstrate a significant anti-inflammatory effect, as determined by changes in cytokine levels pre- and post-treatment [142,143]. The impact of carbamazepine, lamotrigine and antipsychotics on the immune system also remains unclear due to a lack of clinical studies [141].

\section{Conclusions}

Bipolar disorder is strongly associated with immune dysfunction. Moreover, in a subset of BD, immune dysfunction is likely playing a key role in the pathophysiology of disease progression. The bidirectional interaction of BD with immune dysfunction is likely responsible for the high rates of inflammatory comorbidities, such as autoimmune disorders, cardiovascular disease and metabolic disturbances. This interaction is of particular importance as medical comorbidity is primarily responsible for early mortality in $\mathrm{BD}$. Numerous biological mechanisms of the inflammatory-mood pathway have been identified that may present novel targets in the treatment of BD. Targeting the immune system shows promise for improving BD outcomes as it may allow for disease modification through treatment of the underlying etiology (i.e., immune dysfunction), rather than only superficially treating the downstream effects as symptoms arise. Numerous proof-of-concept clinical trials have demonstrated a positive effect of anti-inflammatory agents in BD with generally good tolerability. Currently available evidence suggests that anti-inflammatory agents may be specifically helpful in the treatment of bipolar depression. Conversely, the impact of anti-inflammatory agents in mania and hypomania remains unclear. Clinical studies have also suggested that anti-inflammatory agents may be only beneficial for a subset of BD patients, namely, patients with immune dysfunction, as indicated by elevation of inflammatory markers. As such, future clinical trials should stratify patients based on inflammatory profile to determine which specific anti-inflammatory agent(s) are efficacious in which specific subset of BD patients. 
Author Contributions: J.D.R. and R.S.M. conceived the aim and outline of the current paper. J.D.R. wrote the initial draft of the paper. R.S.M. provided revisions to the paper prior to initial submission.

Conflicts of Interest: J.D.R. declares no conflicts of interest. R.S.M. has received research grant support from Lundbeck, Astra Zeneca, Pfizer, Shire, Otsuka, Bristol Myers Squibb, National Institute of Mental Health, Stanley Medical Research Institute, Canadian Institutes for Health Research, and The Brain and Behavior Research Foundation. RSM has also received speaker/consultant fees from Lundbeck, Pfizer, Astra Zeneca, Elli Lilly, Janssen Ortho, Sunovion, Takeda, Forest, Otsuka, Bristol Myers Squibb and Shire.

\section{References}

1. Rosenblat, J.D.; McIntyre, R.S. Bipolar Disorder and Inflammation. Psychiatr. Clin. N. Am. 2016, 39, $125-137$. [CrossRef] [PubMed]

2. Horrobin, D.F.; Lieb, J. A biochemical basis for the actions of lithium on behaviour and on immunity: Relapsing and remitting disorders of inflammation and immunity such as multiple sclerosis or recurrent herpes as manic-depression of the immune system. Med. Hypotheses 1981, 7, 891-905. [CrossRef]

3. Modabbernia, A.; Taslimi, S.; Brietzke, E.; Ashrafi, M. Cytokine alterations in bipolar disorder: A meta-analysis of 30 studies. Biol. Psychiatry 2013, 74, 15-25. [CrossRef] [PubMed]

4. Munkholm, K.; Vinberg, M.; Vedel Kessing, L. Cytokines in bipolar disorder: A systematic review and meta-analysis. J. Affect. Disord. 2013, 144, 16-27. [CrossRef] [PubMed]

5. Munkholm, K.; Brauner, J.V.; Kessing, L.V.; Vinberg, M. Cytokines in bipolar disorder vs. healthy control subjects: A systematic review and meta-analysis. J. Psychiatr. Res. 2013, 47, 1119-1133. [CrossRef] [PubMed]

6. Rosenblat, J.D.; McIntyre, R.S. Are medical comorbid conditions of bipolar disorder due to immune dysfunction? Acta Psychiatr. Scand. 2015, 132, 180-191. [CrossRef] [PubMed]

7. Dantzer, R.; O'Connor, J.C.; Freund, G.G.; Johnson, R.W.; Kelley, K.W. From inflammation to sickness and depression: When the immune system subjugates the brain. Nat. Rev. Neurosci. 2008, 9, 46-56. [CrossRef] [PubMed]

8. Raison, C.L.; Miller, A.H. Malaise, melancholia and madness: The evolutionary legacy of an inflammatory bias. Brain Behav. Immun. 2013, 31, 1-8. [CrossRef] [PubMed]

9. Miller, A.H.; Maletic, V.; Raison, C.L. Inflammation and its discontents: The role of cytokines in the pathophysiology of major depression. Biol. Psychiatry 2009, 65, 732-741. [CrossRef] [PubMed]

10. Rosenblat, J.D.; Cha, D.S.; Mansur, R.B.; McIntyre, R.S. Inflamed moods: A review of the interactions between inflammation and mood disorders. Prog. Neuro-Psychopharmacol. Biol. Psychiatry 2014, 53, 23-34. [CrossRef] [PubMed]

11. Abbas, A.K.; Lichtman, A.H.; Pillai, S. Cellular and Molecular Immunology, 7th ed.; Elsevier Saunders: Philadelphia, PA, USA, 2012.

12. Perugi, G.; Quaranta, G.; Belletti, S.; Casalini, F.; Mosti, N.; Toni, C.; DellOsso, L. General medical conditions in 347 bipolar disorder patients: Clinical correlates of metabolic and autoimmune-allergic diseases. J. Affect. Disord. 2014, 170C, 95-103. [CrossRef] [PubMed]

13. Eaton, W.W.; Pedersen, M.G.; Nielsen, P.R.; Mortensen, P.B. Autoimmune diseases, bipolar disorder, and non-affective psychosis. Bipolar Disord. 2010, 12, 638-646. [CrossRef] [PubMed]

14. Bachen, E.A.; Chesney, M.A.; Criswell, L.A. Prevalence of mood and anxiety disorders in women with systemic lupus erythematosus. Arthritis Rheum. 2009, 61, 822-829. [CrossRef] [PubMed]

15. Kupka, R.W.; Nolen, W.A.; Post, R.M.; McElroy, S.L.; Altshuler, L.L.; Denicoff, K.D.; Frye, M.A.; Keck, P.E., Jr.; Leverich, G.S.; Rush, A.J.; et al. High rate of autoimmune thyroiditis in bipolar disorder: Lack of association with lithium exposure. Biol. Psychiatry 2002, 51, 305-311. [CrossRef]

16. Hsu, C.C.; Chen, S.C.; Liu, C.J.; Lu, T.; Shen, C.C.; Hu, Y.W.; Yeh, C.M.; Chen, P.M.; Chen, T.J.; Hu, L.Y. Rheumatoid arthritis and the risk of bipolar disorder: A nationwide population-based study. PLoS ONE 2014, 9, e107512. [CrossRef] [PubMed]

17. Edwards, L.J.; Constantinescu, C.S. A prospective study of conditions associated with multiple sclerosis in a cohort of 658 consecutive outpatients attending a multiple sclerosis clinic. Mult. Scler. 2004, 10, 575-581. [CrossRef] [PubMed]

18. Han, C.; Lofland, J.H.; Zhao, N.; Schenkel, B. Increased prevalence of psychiatric disorders and health care-associated costs among patients with moderate-to-severe psoriasis. J. Drugs Dermatol. JDD 2011, 10, 843-850. [PubMed] 
19. Medzhitov, R. Origin and physiological roles of inflammation. Nature 2008, 454, 428-435. [CrossRef] [PubMed]

20. Yolken, R.H.; Torrey, E.F. Viruses, schizophrenia, and bipolar disorder. Clin. Microbiol. Rev. 1995, 8, 131-145. [PubMed]

21. Sutterland, A.L.; Fond, G.; Kuin, A.; Koeter, M.W.; Lutter, R.; van Gool, T.; Yolken, R.; Szoke, A.; Leboyer, M.; de Haan, L. Beyond the association. Toxoplasma gondii in schizophrenia, bipolar disorder, and addiction: Systematic review and meta-analysis. Acta Psychiatr. Scand. 2015, 132, 161-179. [CrossRef] [PubMed]

22. Hamdani, N.; Daban-Huard, C.; Lajnef, M.; Gadel, R.; Le Corvoisier, P.; Delavest, M.; Carde, S.; Lepine, J.P.; Jamain, S.; Houenou, J.; et al. Cognitive deterioration among bipolar disorder patients infected by Toxoplasma gondii is correlated to interleukin 6 levels. J. Affect. Disord. 2015, 179, 161-166. [CrossRef] [PubMed]

23. Rosenblat, J.D.; Brietzke, E.; Mansur, R.B.; Maruschak, N.A.; Lee, Y.; McIntyre, R.S. Inflammation as a neurobiological substrate of cognitive impairment in bipolar disorder: Evidence, pathophysiology and treatment implications. J. Affect. Disord. 2015, 188, 149-159. [CrossRef] [PubMed]

24. Libby, P.; Ridker, P.M.; Maseri, A. Inflammation and atherosclerosis. Circulation 2002, 105, 1135-1143. [CrossRef] [PubMed]

25. SayuriYamagata, A.; Brietzke, E.; Rosenblat, J.D.; Kakar, R.; McIntyre, R.S. Medical comorbidity in bipolar disorder: The link with metabolic-inflammatory systems. J. Affect. Disord. 2017, 211, 99-106. [CrossRef] [PubMed]

26. McElroy, S.L.; Keck, P.E., Jr. Metabolic syndrome in bipolar disorder: A review with a focus on bipolar depression. J. Clin. Psychiatry 2014, 75, 46-61. [CrossRef] [PubMed]

27. Young, A.H.; Grunze, H. Physical health of patients with bipolar disorder. Acta Psychiatr. Scand. 2013, 127, 3-10. [CrossRef] [PubMed]

28. Swartz, H.A.; Fagiolini, A. Cardiovascular disease and bipolar disorder: Risk and clinical implications. J. Clin. Psychiatry 2012, 73, 1563-1565. [CrossRef] [PubMed]

29. Fenton, W.S.; Stover, E.S. Mood disorders: Cardiovascular and diabetes comorbidity. Curr. Opin. Psychiatry 2006, 19, 421-427. [CrossRef] [PubMed]

30. Klumpers, U.M.; Boom, K.; Janssen, F.M.; Tulen, J.H.; Loonen, A.J. Cardiovascular risk factors in outpatients with bipolar disorder. Pharmacopsychiatry 2004, 37, 211-216. [CrossRef] [PubMed]

31. Kessing, L.V.; Vradi, E.; McIntyre, R.S.; Andersen, P.K. Causes of decreased life expectancy over the life span in bipolar disorder. J. Affect. Disord. 2015, 180, 142-147. [CrossRef] [PubMed]

32. Purkayastha, S.; Cai, D. Neuroinflammatory basis of metabolic syndrome. Mol. Metab. 2013, 2, 356-363. [CrossRef] [PubMed]

33. Soczynska, J.K.; Kennedy, S.H.; Woldeyohannes, H.O.; Liauw, S.S.; Alsuwaidan, M.; Yim, C.Y.; McIntyre, R.S. Mood disorders and obesity: Understanding inflammation as a pathophysiological nexus. Neuromol. Med. 2011, 13, 93-116. [CrossRef] [PubMed]

34. Mansur, R.B.; Brietzke, E.; McIntyre, R.S. Is there a "metabolic-mood syndrome"? A review of the relationship between obesity and mood disorders. Neurosci. Biobehav. Rev. 2015, 52, 89-104. [CrossRef] [PubMed]

35. Calkin, C.; van de Velde, C.; Ruzickova, M.; Slaney, C.; Garnham, J.; Hajek, T.; O’Donovan, C.; Alda, M. Can body mass index help predict outcome in patients with bipolar disorder? Bipolar Disord. 2009, 11, 650-656. [CrossRef] [PubMed]

36. McIntyre, R.S.; Konarski, J.Z.; Misener, V.L.; Kennedy, S.H. Bipolar disorder and diabetes mellitus: epidemiology, etiology, and treatment implications. Ann. Clin. Psychiatry 2005, 17, 83-93. [CrossRef] [PubMed]

37. Mathieu, P.; Lemieux, I.; Despres, J.P. Obesity, inflammation, and cardiovascular risk. Clin. Pharmacol. Ther. 2010, 87, 407-416. [CrossRef] [PubMed]

38. Mathieu, P.; Pibarot, P.; Larose, E.; Poirier, P.; Marette, A.; Despres, J.P. Visceral obesity and the heart. Int. J. Biochem. Cell Biol. 2008, 40, 821-836. [CrossRef] [PubMed]

39. Unger, R.H. Longevity, lipotoxicity and leptin: The adipocyte defense against feasting and famine. Biochimie 2005, 87, 57-64. [CrossRef] [PubMed]

40. Spalding, K.L.; Arner, E.; Westermark, P.O.; Bernard, S.; Buchholz, B.A.; Bergmann, O.; Blomqvist, L.; Hoffstedt, J.; Naslund, E.; Britton, T.; et al. Dynamics of fat cell turnover in humans. Nature 2008, 453, 783-787. [CrossRef] [PubMed] 
41. Chung, K.H.; Huang, C.C.; Lin, H.C. Increased risk of gout among patients with bipolar disorder: A nationwide population-based study. Psychiatry Res. 2010, 180, 147-150. [CrossRef] [PubMed]

42. Cheffer, A.; Castillo, A.R.G.; Correa-Velloso, J.; Goncalves, M.C.B.; Naaldijk, Y.; Nascimento, I.C.; Burnstock, G.; Ulrich, H. Purinergic system in psychiatric diseases. Mol. Psychiatry 2017. [CrossRef] [PubMed]

43. Bartoli, F.; Crocamo, C.; Mazza, M.G.; Clerici, M.; Carra, G. Uric acid levels in subjects with bipolar disorder: A comparative meta-analysis. J. Psychiatr. Res. 2016, 81, 133-139. [CrossRef] [PubMed]

44. Yuan, H.; Yu, C.; Li, X.; Sun, L.; Zhu, X.; Zhao, C.; Zhang, Z.; Yang, Z. Serum Uric Acid Levels and Risk of Metabolic Syndrome: A Dose-Response Meta-Analysis of Prospective Studies. J. Clin. Endocrinol. Metab. 2015, 100, 4198-4207. [CrossRef] [PubMed]

45. Martinon, F. Update on biology: Uric acid and the activation of immune and inflammatory cells. Curr. Rheumatol. Rep. 2010, 12, 135-141. [CrossRef] [PubMed]

46. Bartoli, F.; Crocamo, C.; Clerici, M.; Carra, G. Allopurinol as add-on treatment for mania symptoms in bipolar disorder: Systematic review and meta-analysis of randomised controlled trials. Br. J. Psychiatry 2017, 210, 10-15. [CrossRef] [PubMed]

47. Barbosa, I.G.; Bauer, M.E.; Machado-Vieira, R.; Teixeira, A.L. Cytokines in Bipolar Disorder: Paving the Way for Neuroprogression. Neural Plast. 2014, 2014, 360481. [CrossRef] [PubMed]

48. Brietzke, E.; Kauer-Sant'Anna, M.; Teixeira, A.L.; Kapczinski, F. Abnormalities in serum chemokine levels in euthymic patients with bipolar disorder. Brain Behav. Immun. 2009, 23, 1079-1082. [CrossRef] [PubMed]

49. Brietzke, E.; Stertz, L.; Fernandes, B.S.; Kauer-Sant'anna, M.; Mascarenhas, M.; Escosteguy Vargas, A.; Chies, J.A.; Kapczinski, F. Comparison of cytokine levels in depressed, manic and euthymic patients with bipolar disorder. J. Affect. Disord. 2009, 116, 214-217. [CrossRef] [PubMed]

50. Goldsmith, D.R.; Rapaport, M.H.; Miller, B.J. A meta-analysis of blood cytokine network alterations in psychiatric patients: Comparisons between schizophrenia, bipolar disorder and depression. Mol. Psychiatry 2016, 21, 1696-1709. [CrossRef] [PubMed]

51. Barbosa, I.G.; Machado-Vieira, R.; Soares, J.C.; Teixeira, A.L. The immunology of bipolar disorder. Neuroimmunomodulation 2014, 21, 117-122. [CrossRef] [PubMed]

52. Siwek, M.; Sowa-Kucma, M.; Styczen, K.; Misztak, P.; Nowak, R.J.; Szewczyk, B.; Dudek, D.; Rybakowski, J.K.; Nowak, G.; Maes, M. Associations of Serum Cytokine Receptor Levels with Melancholia, Staging of Illness, Depressive and Manic Phases, and Severity of Depression in Bipolar Disorder. Mol. Neurobiol. 2016, 54, 5883-5893. [CrossRef] [PubMed]

53. McNamara, R.K.; Lotrich, F.E. Elevated immune-inflammatory signaling in mood disorders: A new therapeutic target? Expert Rev. Neurother. 2012, 12, 1143-1161. [CrossRef] [PubMed]

54. Setiawan, E.; Wilson, A.A.; Mizrahi, R.; Rusjan, P.M.; Miler, L.; Rajkowska, G.; Suridjan, I.; Kennedy, J.L.; Rekkas, P.V.; Houle, S.; et al. Role of translocator protein density, a marker of neuroinflammation, in the brain during major depressive episodes. JAMA Psychiatry 2015, 72, 268-275. [CrossRef] [PubMed]

55. Swardfager, W.; Rosenblat, J.D.; Benlamri, M.; McIntyre, R.S. Mapping inflammation onto mood: Inflammatory mediators of anhedonia. Neurosci. Biobehav. Rev. 2016, 64, 148-166. [CrossRef] [PubMed]

56. Reus, G.Z.; Fries, G.R.; Stertz, L.; Badawy, M.; Passos, I.C.; Barichello, T.; Kapczinski, F.; Quevedo, J. The role of inflammation and microglial activation in the pathophysiology of psychiatric disorders. Neuroscience 2015, 300, 141-154. [CrossRef] [PubMed]

57. Banks, W.A.; Erickson, M.A. The blood-brain barrier and immune function and dysfunction. Neurobiol. Dis. 2010, 37, 26-32. [CrossRef] [PubMed]

58. Louveau, A.; Smirnov, I.; Keyes, T.J.; Eccles, J.D.; Rouhani, S.J.; Peske, J.D.; Derecki, N.C.; Castle, D.; Mandell, J.W.; Lee, K.S.; et al. Structural and functional features of central nervous system lymphatic vessels. Nature 2015, 523, 337-341. [CrossRef] [PubMed]

59. Lopez-Munoz, F; Alamo, C. Monoaminergic neurotransmission: The history of the discovery of antidepressants from 1950s until today. Curr. Pharm. Des. 2009, 15, 1563-1586. [CrossRef] [PubMed]

60. Capuron, L.; Neurauter, G.; Musselman, D.L.; Lawson, D.H.; Nemeroff, C.B.; Fuchs, D.; Miller, A.H. Interferon-alpha-induced changes in tryptophan metabolism. relationship to depression and paroxetine treatment. Biol. Psychiatry 2003, 54, 906-914. [CrossRef]

61. Wang, J.; Dunn, A.J. Mouse interleukin-6 stimulates the HPA axis and increases brain tryptophan and serotonin metabolism. Neurochem. Int. 1998, 33, 143-154. [CrossRef] 
62. Arango, V.; Underwood, M.D.; Mann, J.J. Serotonin brain circuits involved in major depression and suicide. Prog. Brain Res. 2002, 136, 443-453. [PubMed]

63. Maes, M.; Ringel, K.; Kubera, M.; Berk, M.; Rybakowski, J. Increased autoimmune activity against 5-HT: A key component of depression that is associated with inflammation and activation of cell-mediated immunity, and with severity and staging of depression. J. Affect. Disord. 2012, 136, 386-392. [CrossRef] [PubMed]

64. Murr, C.; Widner, B.; Wirleitner, B.; Fuchs, D. Neopterin as a marker for immune system activation. Curr. Drug Metab. 2002, 3, 175-187. [CrossRef] [PubMed]

65. Maes, M.; Bosmans, E.; Scharpe, S.; D’Hondt, P.; Desnyder, R. Plasma soluble interleukin-2-receptor in depression: Relationships to plasma neopterin and serum IL-2 concentrations and HPA-axis activity. Eur. Psychiatry 1995, 10, 397-403. [CrossRef]

66. Li, W.; Knowlton, D.; Woodward, W.R.; Habecker, B.A. Regulation of noradrenergic function by inflammatory cytokines and depolarization. J. Neurochem. 2003, 86, 774-783. [CrossRef] [PubMed]

67. Capuron, L.; Schroecksnadel, S.; Feart, C.; Aubert, A.; Higueret, D.; Barberger-Gateau, P.; Laye, S.; Fuchs, D. Chronic low-grade inflammation in elderly persons is associated with altered tryptophan and tyrosine metabolism: Role in neuropsychiatric symptoms. Biol. Psychiatry 2011, 70, 175-182. [CrossRef] [PubMed]

68. Kishimoto, T.; Chawla, J.M.; Hagi, K.; Zarate, C.A.; Kane, J.M.; Bauer, M.; Correll, C.U. Single-dose infusion ketamine and non-ketamine N-methyl-d-aspartate receptor antagonists for unipolar and bipolar depression: A meta-analysis of efficacy, safety and time trajectories. Psychol. Med. 2016, 46, 1459-1472. [CrossRef] [PubMed]

69. Serafini, G.; Howland, R.H.; Rovedi, F.; Girardi, P.; Amore, M. The role of ketamine in treatment-resistant depression: A systematic review. Curr. Neuropharmacol. 2014, 12, 444-461. [CrossRef] [PubMed]

70. Haroon, E.; Miller, A.H. Inflammation Effects on Brain Glutamate in Depression: Mechanistic Considerations and Treatment Implications. Curr. Top. Behav. Neurosci. 2017, 31, 173-198. [PubMed]

71. Dantzer, R.; Walker, A.K. Is there a role for glutamate-mediated excitotoxicity in inflammation-induced depression? J. Neural Transm. 2014, 121, 925-932. [CrossRef] [PubMed]

72. Haroon, E.; Woolwine, B.J.; Chen, X.; Pace, T.W.; Parekh, S.; Spivey, J.R.; Hu, X.P.; Miller, A.H. IFN-alpha-induced cortical and subcortical glutamate changes assessed by magnetic resonance spectroscopy. Neuropsychopharmacology 2014, 39, 1777-1785. [CrossRef] [PubMed]

73. Haroon, E.; Fleischer, C.C.; Felger, J.C.; Chen, X.; Woolwine, B.J.; Patel, T.; Hu, X.P.; Miller, A.H. Conceptual convergence: Increased inflammation is associated with increased basal ganglia glutamate in patients with major depression. Mol. Psychiatry 2016, 21, 1351-1357. [CrossRef] [PubMed]

74. Yang, J.J.; Wang, N.; Yang, C.; Shi, J.Y.; Yu, H.Y.; Hashimoto, K. Serum interleukin-6 is a predictive biomarker for ketamine's antidepressant effect in treatment-resistant patients with major depression. Biol. Psychiatry 2015, 77, e19-e20. [CrossRef] [PubMed]

75. Machado-Vieira, R.; Gold, P.W.; Luckenbaugh, D.A.; Ballard, E.D.; Richards, E.M.; Henter, I.D.; De Sousa, R.T.; Niciu, M.J.; Yuan, P.; Zarate, C.A., Jr. The role of adipokines in the rapid antidepressant effects of ketamine. Mol. Psychiatry 2017, 22, 127-133. [CrossRef] [PubMed]

76. Frick, L.R.; Williams, K.; Pittenger, C. Microglial dysregulation in psychiatric disease. Clin. Dev. Immunol. 2013, 2013, 608654. [CrossRef] [PubMed]

77. Ekdahl, C.T. Microglial activation-Tuning and pruning adult neurogenesis. Front. Pharmacol. $2012,3,41$. [CrossRef] [PubMed]

78. Harry, G.J.; Kraft, A.D. Microglia in the developing brain: A potential target with lifetime effects. Neurotoxicology 2012, 33, 191-206. [CrossRef] [PubMed]

79. Haarman, B.C.; Riemersma-Van der Lek, R.F.; de Groot, J.C.; Ruhe, H.G.; Klein, H.C.; Zandstra, T.E.; Burger, H.; Schoevers, R.A.; de Vries, E.F.; Drexhage, H.A.; et al. Neuroinflammation in bipolar disorder-A [(11)C]-(R)-PK11195 positron emission tomography study. Brain Behav. Immun. 2014, 40, 219-225. [CrossRef] [PubMed]

80. Stertz, L.; Magalhaes, P.V.; Kapczinski, F. Is bipolar disorder an inflammatory condition? The relevance of microglial activation. Curr. Opin. Psychiatry 2013, 26, 19-26. [CrossRef] [PubMed]

81. Strejilevich, S.A.; Samame, C.; Martino, D.J. The trajectory of neuropsychological dysfunctions in bipolar disorders: A critical examination of a hypothesis. J. Affect. Disord. 2015, 175, 396-402. [CrossRef] [PubMed] 
82. Rizzo, L.B.; Costa, L.G.; Mansur, R.B.; Swardfager, W.; Belangero, S.I.; Grassi-Oliveira, R.; McIntyre, R.S.; Bauer, M.E.; Brietzke, E. The theory of bipolar disorder as an illness of accelerated aging: Implications for clinical care and research. Neurosci. Biobehav. Rev. 2014, 42, 157-169. [CrossRef] [PubMed]

83. Mansur, R.B.; Cha, D.S.; Asevedo, E.; McIntyre, R.S.; Brietzke, E. Selfish brain and neuroprogression in bipolar disorder. Prog. Neuro-Psychopharmacol. Biol. Psychiatry 2013, 43, 66-71. [CrossRef] [PubMed]

84. Gill, R.; Tsung, A.; Billiar, T. Linking oxidative stress to inflammation: Toll-like receptors. Free Radic. Biol. Med. 2010, 48, 1121-1132. [CrossRef] [PubMed]

85. Lee, S.Y.; Lee, S.J.; Han, C.; Patkar, A.A.; Masand, P.S.; Pae, C.U. Oxidative/nitrosative stress and antidepressants: Targets for novel antidepressants. Prog. Neuro-Psychopharmacol. Biol. Psychiatry 2013, 46, 224-235.

86. Moylan, S.; Berk, M.; Dean, O.M.; Samuni, Y.; Williams, L.J.; O’Neil, A.; Hayley, A.C.; Pasco, J.A.; Anderson, G.; Jacka, F.N.; et al. Oxidative \& nitrosative stress in depression: Why so much stress? Neurosci. Biobehav. Rev. 2014, 45, 46-62. [PubMed]

87. Jimenez-Fernandez, S.; Gurpegui, M.; Diaz-Atienza, F.; Perez-Costillas, L.; Gerstenberg, M.; Correll, C.U. Oxidative stress and antioxidant parameters in patients with major depressive disorder compared to healthy controls before and after antidepressant treatment: Results from a meta-analysis. J. Clin. Psychiatry 2015, 76, 1658-1667. [CrossRef] [PubMed]

88. Berk, M.; Kapczinski, F.; Andreazza, A.C.; Dean, O.M.; Giorlando, F.; Maes, M.; Yucel, M.; Gama, C.S.; Dodd, S.; Dean, B.; et al. Pathways underlying neuroprogression in bipolar disorder: Focus on inflammation, oxidative stress and neurotrophic factors. Neurosci. Biobehav. Rev. 2011, 35, 804-817. [CrossRef] [PubMed]

89. Palta, P.; Samuel, L.J.; Miller, E.R., 3rd; Szanton, S.L. Depression and oxidative stress: Results from a meta-analysis of observational studies. Psychosom. Med. 2014, 76, 12-19. [CrossRef] [PubMed]

90. Black, C.N.; Bot, M.; Scheffer, P.G.; Cuijpers, P.; Penninx, B.W. Is depression associated with increased oxidative stress? A systematic review and meta-analysis. Psychoneuroendocrinology 2015, 51, 164-175. [CrossRef] [PubMed]

91. Maurya, P.K.; Noto, C.; Rizzo, L.B.; Rios, A.C.; Nunes, S.O.; Barbosa, D.S.; Sethi, S.; Zeni, M.; Mansur, R.B.; Maes, M.; et al. The role of oxidative and nitrosative stress in accelerated aging and major depressive disorder. Prog. Neuro-Psychopharmacol. Biol. Psychiatry 2016, 65, 134-144. [CrossRef] [PubMed]

92. Beishuizen, A.; Thijs, L.G. Endotoxin and the hypothalamo-pituitary-adrenal (HPA) axis. J. Endotoxin Res. 2003, 9, 3-24. [PubMed]

93. Boutzios, G.; Kaltsas, G. Immune System Effects on the Endocrine System. Available online: https: / /www.ncbi. nlm.nih.gov/books/NBK279139/ (accessed on 29 October 2017).

94. Pace, T.W.; Miller, A.H. Cytokines and glucocorticoid receptor signaling. Relevance to major depression. Ann. N. Y. Acad. Sci. 2009, 1179, 86-105. [CrossRef] [PubMed]

95. Murphy, B.E. Steroids and depression. J. Steroid Biochem. Mol. Biol. 1991, 38, 537-559. [CrossRef]

96. Fries, G.R.; Vasconcelos-Moreno, M.P.; Gubert, C.; dos Santos, B.T.; Sartori, J.; Eisele, B.; Ferrari, P.; Fijtman, A.; Ruegg, J.; Gassen, N.C.; et al. Hypothalamic-pituitary-adrenal axis dysfunction and illness progression in bipolar disorder. Int. J. Neuropsychopharmacol. 2014, 18. [CrossRef] [PubMed]

97. Young, A.H. The effects of HPA axis function on cognition and its implications for the pathophysiology of bipolar disorder. Harv. Rev. Psychiatry 2014, 22, 331-333. [CrossRef] [PubMed]

98. Cowen, P.J. Not fade away: The HPA axis and depression. Psychol. Med. 2010, 40, 1-4. [CrossRef] [PubMed]

99. Belvederi Murri, M.; Prestia, D.; Mondelli, V.; Pariante, C.; Patti, S.; Olivieri, B.; Arzani, C.; Masotti, M.; Respino, M.; Antonioli, M.; et al. The HPA axis in bipolar disorder: Systematic review and meta-analysis. Psychoneuroendocrinology 2016, 63, 327-342. [CrossRef] [PubMed]

100. Bested, A.C.; Logan, A.C.; Selhub, E.M. Intestinal microbiota, probiotics and mental health: From Metchnikoff to modern advances: Part I-Autointoxication revisited. Gut Pathog. 2013, 5, 5. [CrossRef] [PubMed]

101. Cryan, J.F.; Dinan, T.G. Mind-altering microorganisms: The impact of the gut microbiota on brain and behaviour. Nat. Rev. Neurosci. 2012, 13, 701-712. [CrossRef] [PubMed]

102. Bercik, P. The microbiota-gut-brain axis: Learning from intestinal bacteria? Gut 2011, 60, 288-289. [CrossRef] [PubMed]

103. Alam, R.; Abdolmaleky, H.M.; Zhou, J.R. Microbiome, inflammation, epigenetic alterations, and mental diseases. Am. J. Med. Genet. B Neuropsychiatr. Genet. 2017, 174, 651-660. [CrossRef] [PubMed] 
104. Hamdani, N.; Boukouaci, W.; Hallouche, M.R.; Charron, D.; Krishnamoorthy, R.; Leboyer, M.; Tamouza, R. Resolution of a manic episode treated with activated charcoal: Evidence for a brain-gut axis in bipolar disorder. Aust. N. Z. J. Psychiatry 2015, 49, 1221-1223. [CrossRef] [PubMed]

105. Harvey, A.G. Sleep and circadian rhythms in bipolar disorder: Seeking synchrony, harmony, and regulation. Am. J. Psychiatry 2008, 165, 820-829. [CrossRef] [PubMed]

106. McIntyre, R.S. Sleep and Inflammation: Implications for Domain Approach and Treatment Opportunities. Biol. Psychiatry 2016, 80, 9-11. [CrossRef] [PubMed]

107. Irwin, M.R.; Olmstead, R.; Carroll, J.E. Sleep Disturbance, Sleep Duration, and Inflammation: A Systematic Review and Meta-Analysis of Cohort Studies and Experimental Sleep Deprivation. Biol. Psychiatry 2016, 80, 40-52. [CrossRef] [PubMed]

108. Mukherjee, D.; Krishnamurthy, V.B.; Millett, C.E.; Reider, A.; Can, A.; Groer, M.; Fuchs, D.; Postolache, T.T.; Saunders, E.F.H. Total sleep time and kynurenine metabolism associated with mood symptom severity in bipolar disorder. Bipolar Disord. 2017. [CrossRef] [PubMed]

109. Dolsen, M.R.; Soehner, A.M.; Harvey, A.G. Pro-inflammatory cytokines, mood, and sleep in interepisode bipolar disorder and insomnia: A pilot study with implications for psychosocial interventions. Psychosom. Med. 2017. [CrossRef] [PubMed]

110. Gitlin, M. Treatment-resistant bipolar disorder. Mol. Psychiatry 2006, 11, 227-240. [CrossRef] [PubMed]

111. Bak, M.; Fransen, A.; Janssen, J.; van Os, J.; Drukker, M. Almost all antipsychotics result in weight gain: A meta-analysis. PLoS ONE 2014, 9, e94112. [CrossRef] [PubMed]

112. Kohler, O.; Benros, M.E.; Nordentoft, M.; Farkouh, M.E.; Iyengar, R.L.; Mors, O.; Krogh, J. Effect of Anti-inflammatory Treatment on Depression, Depressive Symptoms, and Adverse Effects: A Systematic Review and Meta-analysis of Randomized Clinical Trials. JAMA Psychiatry 2014, 71, 1381-1391. [CrossRef] [PubMed]

113. Rosenblat, J.D.; Kakar, R.; Berk, M.; Kessing, L.V.; Vinberg, M.; Baune, B.T.; Mansur, R.B.; Brietzke, E.; Goldstein, B.I.; McIntyre, R.S. Anti-inflammatory agents in the treatment of bipolar depression: A systematic review and meta-analysis. Bipolar Disord. 2016, 18, 89-101. [CrossRef] [PubMed]

114. Berk, M.; Copolov, D.L.; Dean, O.; Lu, K.; Jeavons, S.; Schapkaitz, I.; Anderson-Hunt, M.; Bush, A.I. N-acetyl cysteine for depressive symptoms in bipolar disorder-A double-blind randomized placebo-controlled trial. Biol. Psychiatry 2008, 64, 468-475. [CrossRef] [PubMed]

115. Berk, M.; Dean, O.M.; Cotton, S.M.; Gama, C.S.; Kapczinski, F.; Fernandes, B.; Kohlmann, K.; Jeavons, S.; Hewitt, K.; Moss, K.; et al. Maintenance $N$-acetyl cysteine treatment for bipolar disorder: A double-blind randomized placebo controlled trial. BMC Med. 2012, 10, 91. [CrossRef] [PubMed]

116. Magalhaes, P.V.; Dean, O.M.; Bush, A.I.; Copolov, D.L.; Malhi, G.S.; Kohlmann, K.; Jeavons, S.; Schapkaitz, I.; Anderson-Hunt, M.; Berk, M. N-acetylcysteine for major depressive episodes in bipolar disorder. Rev. Bras. Psiquiatr. 2011, 33, 374-378. [CrossRef] [PubMed]

117. Berk, M.; Dean, O.; Cotton, S.M.; Gama, C.S.; Kapczinski, F.; Fernandes, B.S.; Kohlmann, K.; Jeavons, S.; Hewitt, K.; Allwang, C.; et al. The efficacy of $N$-acetylcysteine as an adjunctive treatment in bipolar depression: An open label trial. J. Affect. Disord. 2011, 135, 389-394. [CrossRef] [PubMed]

118. Magalhaes, P.V.; Dean, O.M.; Bush, A.I.; Copolov, D.L.; Malhi, G.S.; Kohlmann, K.; Jeavons, S.; Schapkaitz, I.; Anderson-Hunt, M.; Berk, M. A preliminary investigation on the efficacy of $N$-acetyl cysteine for mania or hypomania. Aust. N. Z. J. Psychiatry 2013, 47, 564-568. [CrossRef] [PubMed]

119. Bloch, M.H.; Hannestad, J. Omega-3 fatty acids for the treatment of depression: Systematic review and meta-analysis. Mol. Psychiatry 2012, 17, 1272-1282. [CrossRef] [PubMed]

120. Stoll, A.L.; Severus, W.E.; Freeman, M.P.; Rueter, S.; Zboyan, H.A.; Diamond, E.; Cress, K.K.; Marangell, L.B. Omega 3 fatty acids in bipolar disorder: A preliminary double-blind, placebo-controlled trial. Arch. Gen. Psychiatry 1999, 56, 407-412. [CrossRef] [PubMed]

121. Frangou, S.; Lewis, M.; McCrone, P. Efficacy of ethyl-eicosapentaenoic acid in bipolar depression: Randomised double-blind placebo-controlled study. Br. J. Psychiatry J. Ment. Sci. 2006, 188, 46-50. [CrossRef] [PubMed]

122. Frangou, S.; Lewis, M.; Wollard, J.; Simmons, A. Preliminary in vivo evidence of increased N-acetyl-aspartate following eicosapentanoic acid treatment in patients with bipolar disorder. J. Psychopharmacol. 2007, 21, 435-439. [CrossRef] [PubMed] 
123. Keck, P.E., Jr.; Mintz, J.; McElroy, S.L.; Freeman, M.P.; Suppes, T.; Frye, M.A.; Altshuler, L.L.; Kupka, R.; Nolen, W.A.; Leverich, G.S.; et al. Double-blind, randomized, placebo-controlled trials of ethyl-eicosapentanoate in the treatment of bipolar depression and rapid cycling bipolar disorder. Biol. Psychiatry 2006, 60, 1020-1022. [CrossRef] [PubMed]

124. Hirashima, F.; Parow, A.M.; Stoll, A.L.; Demopulos, C.M.; Damico, K.E.; Rohan, M.L.; Eskesen, J.G.; Zuo, C.S.; Cohen, B.M.; Renshaw, P.F. Omega-3 fatty acid treatment and T(2) whole brain relaxation times in bipolar disorder. Am. J. Psychiatry 2004, 161, 1922-1924. [CrossRef] [PubMed]

125. Rapaport, M.H.; Nierenberg, A.A.; Schettler, P.J.; Kinkead, B.; Cardoos, A.; Walker, R.; Mischoulon, D. Inflammation as a predictive biomarker for response to omega-3 fatty acids in major depressive disorder: A proof-of-concept study. Mol. Psychiatry 2016, 21, 71-79. [CrossRef] [PubMed]

126. Nery, F.G.; Monkul, E.S.; Hatch, J.P.; Fonseca, M.; Zunta-Soares, G.B.; Frey, B.N.; Bowden, C.L.; Soares, J.C. Celecoxib as an adjunct in the treatment of depressive or mixed episodes of bipolar disorder: A double-blind, randomized, placebo-controlled study. Hum. Psychopharmacol. 2008, 23, 87-94. [CrossRef] [PubMed]

127. Saroukhani, S.; Emami-Parsa, M.; Modabbernia, A.; Ashrafi, M.; Farokhnia, M.; Hajiaghaee, R.; Akhondzadeh, S. Aspirin for treatment of lithium-associated sexual dysfunction in men: Randomized double-blind placebo-controlled study. Bipolar Disord. 2013, 15, 650-656. [CrossRef] [PubMed]

128. Arabzadeh, S.; Ameli, N.; Zeinoddini, A.; Rezaei, F.; Farokhnia, M.; Mohammadinejad, P.; Ghaleiha, A.; Akhondzadeh, S. Celecoxib adjunctive therapy for acute bipolar mania: A randomized, double-blind, placebo-controlled trial. Bipolar Disord. 2015, 17, 606-614. [CrossRef] [PubMed]

129. Mousavi, S.Y.; Khezri, R.; Karkhaneh-Yousefi, M.A.; Mohammadinejad, P.; Gholamian, F.; Mohammadi, M.R.; Zeinoddini, A.; Akhondzadeh, S. A Randomized, Double-Blind Placebo-Controlled Trial on Effectiveness and Safety of Celecoxib Adjunctive Therapy in Adolescents with Acute Bipolar Mania. J. Child Adolesc. Psychopharmacol. 2017, 27, 494-500. [CrossRef] [PubMed]

130. Kargar, M.; Yoosefi, A.; Akhondzadeh, S.; Artonian, V.; Ashouri, A.; Ghaeli, P. Effect of Adjunctive Celecoxib on BDNF in Manic Patients Undergoing Electroconvulsive Therapy: A Randomized Double Blind Controlled Trial. Pharmacopsychiatry 2015, 48, 268-273. [CrossRef] [PubMed]

131. Soczynska, J.K.; Mansur, R.B.; Brietzke, E.; Swardfager, W.; Kennedy, S.H.; Woldeyohannes, H.O.; Powell, A.M.; Manierka, M.S.; McIntyre, R.S. Novel therapeutic targets in depression: Minocycline as a candidate treatment. Behav. Brain Res. 2012, 235, 302-317. [CrossRef] [PubMed]

132. Levine, J.; Cholestoy, A.; Zimmerman, J. Possible antidepressant effect of minocycline. Am. J. Psychiatry 1996, 153, 582. [PubMed]

133. Miyaoka, T.; Wake, R.; Furuya, M.; Liaury, K.; Ieda, M.; Kawakami, K.; Tsuchie, K.; Taki, M.; Ishihara, K.; Araki, T.; et al. Minocycline as adjunctive therapy for patients with unipolar psychotic depression: An open-label study. Prog. Neuro-Psychopharmacol. Biol. Psychiatry 2012, 37, 222-226. [CrossRef] [PubMed]

134. Soczynska, J.K.; Kennedy, S.H.; Alsuwaidan, M.; Mansur, R.B.; Li, M.; McAndrews, M.P.; Brietzke, E.; Woldeyohannes, H.O.; Taylor, V.H.; McIntyre, R.S. A pilot, open-label, 8-week study evaluating the efficacy, safety and tolerability of adjunctive minocycline for the treatment of bipolar I/II depression. Bipolar Disord. 2017, 19, 198-213. [CrossRef] [PubMed]

135. Dean, O.M.; Kanchanatawan, B.; Ashton, M.; Mohebbi, M.; Ng, C.H.; Maes, M.; Berk, L.; Sughondhabirom, A.; Tangwongchai, S.; Singh, A.B.; et al. Adjunctive minocycline treatment for major depressive disorder: A proof of concept trial. Aust. N. Z. J. Psychiatry 2017, 51, 829-840. [CrossRef] [PubMed]

136. Emadi-Kouchak, H.; Mohammadinejad, P.; Asadollahi-Amin, A.; Rasoulinejad, M.; Zeinoddini, A.; Yalda, A.; Akhondzadeh, S. Therapeutic effects of minocycline on mild-to-moderate depression in HIV patients: A double-blind, placebo-controlled, randomized trial. Int. Clin. Psychopharmacol. 2016, 31, 20-26. [CrossRef] [PubMed]

137. Husain, M.I.; Chaudhry, I.B.; Husain, N.; Khoso, A.B.; Rahman, R.R.; Hamirani, M.M.; Hodsoll, J.; Qurashi, I.; Deakin, J.F.; Young, A.H. Minocycline as an adjunct for treatment-resistant depressive symptoms: A pilot randomised placebo-controlled trial. J. Psychopharmacol. 2017, 31, 1166-1175. [CrossRef] [PubMed]

138. Raison, C.L.; Rutherford, R.E.; Woolwine, B.J.; Shuo, C.; Schettler, P.; Drake, D.F.; Haroon, E.; Miller, A.H. A randomized controlled trial of the tumor necrosis factor antagonist infliximab for treatment-resistant depression: The role of baseline inflammatory biomarkers. JAMA Psychiatry 2013, 70, 31-41. [CrossRef] [PubMed] 
139. Nassar, A.; Azab, A.N. Effects of lithium on inflammation. ACS Chem. Neurosci. 2014, 5, 451-458. [CrossRef] [PubMed]

140. Maddu, N.; Raghavendra, P.B. Review of lithium effects on immune cells. Immunopharmacol. Immunotoxicol. 2015, 37, 111-125. [CrossRef] [PubMed]

141. Van den Ameele, S.; van Diermen, L.; Staels, W.; Coppens, V.; Dumont, G.; Sabbe, B.; Morrens, M. The effect of mood-stabilizing drugs on cytokine levels in bipolar disorder: A systematic review. J. Affect. Disord. 2016, 203, 364-373. [CrossRef] [PubMed]

142. Lee, S.Y.; Chen, S.L.; Chang, Y.H.; Chen, P.S.; Huang, S.Y.; Tzeng, N.S.; Wang, Y.S.; Wang, L.J.; Lee, I.H.; Wang, T.Y.; et al. The effects of add-on low-dose memantine on cytokine levels in bipolar II depression: A 12-week double-blind, randomized controlled trial. J. Clin. Psychopharmacol. 2014, 34, 337-343. [CrossRef] [PubMed]

143. Maes, M.; Bosmans, E.; Calabrese, J.; Smith, R.; Meltzer, H.Y. Interleukin-2 and interleukin-6 in schizophrenia and $\mathrm{m}$ ania: Effects of neuroleptics and mood stabilizers. J. Psychiatr. Res. 1995, 29, 141-152. [CrossRef]

(C) 2017 by the authors. Licensee MDPI, Basel, Switzerland. This article is an open access article distributed under the terms and conditions of the Creative Commons Attribution (CC BY) license (http:/ / creativecommons.org/licenses/by/4.0/). 